\title{
Positron and Positronium Trapping in Heat Treated Zeolites (Ceramics), the Effect of Swift Heavy Ion Irradiation
}

\author{
P. MAJOR ${ }^{a, *}, Z$ s. $\operatorname{KAJCSOS}^{a}$, L. LisZKAY ${ }^{a}, \mathrm{P}$ ZALÁN $^{a}$, \\ C. Kosanović ${ }^{b}$, S. Bosnar ${ }^{b}$, B. Subotićc ${ }^{b}, \mathrm{~K} . \mathrm{LÁzÁR}^{c}$, \\ V.A. Skuratov ${ }^{d}$, K. HavancsáK ${ }^{e}$, P.M. Gordo ${ }^{f}$ \\ AND M.F. FERREIRA MARqUeS ${ }^{g}$ \\ ${ }^{a}$ KFKI Res. Inst. for Part. Nucl. Physics \\ P.O.B. 49, H-1525 Budapest 114, Hungary \\ ${ }^{b}$ Div. of Mater. Chem., Ruder Boskovic Institute \\ Bijenicka 54, P.O.B. 180, Zagreb, Croatia
}

${ }^{c}$ Inst. of Isotopes, HAS, H-1525 Budapest, P.O.B. 77, Hungary

${ }^{d}$ Flerov Laboratory of Nuclear Reactions, Center of Applied Physics, JINR

Ru-141980 Dubna, Russia

${ }^{e}$ Dept. of Mater. Physics, Eötvös Univ.

Pázmány Péter sétány 1A, H-1117 Budapest, Hungary

${ }^{f}$ ICEMS, Dept. of Physics, University of Coimbra

3004-516 Coimbra, Portugal

${ }^{g}$ Dep. de Engenharia Química, Inst. Superior de Engenharia

3031-199 Coimbra, Portugal

A systematic study of zeolite precursor gels, zeolites, and products of their recrystallization to ceramics was carried out in presence of various alkali ions. The investigation of radiation damage induced by high-energy ion beam irradiation with swift heavy ions (Bi ions at $670 \mathrm{MeV}$ energy with $4 \times 10^{12}$ ion $/ \mathrm{cm}^{2}$ fluence) was also included. The shortening of lifetimes found after irradiation in ceramics might probably be ascribed to interactions of $o$-Ps with free radicals and other quenching agents created through the ion irradiation. These lifetime-shortening interactions probably partly hide the $o$-Ps trapping in free volume sites.

PACS numbers: 78.70.Bj, 61.43.Gt, 36.10.Dr, 61.80.Jh

${ }^{*}$ corresponding author; e-mail: majorp@rmki.kfki.hu 


\section{Introduction}

Due to positron and positronium trapping in free-volume sites, positron annihilation lifetime spectroscopy (PALS) allows the investigation of structural imperfections. For trapped long-lived ortho-positronium (o-Ps) states the lifetimes (LT) correlate with the size and the relative intensities with the concentration of the extended traps. Models were developed for spherical [1, 2], rectangular [3] and cylindrical [4] shapes. In this work structural changes were investigated, also on swift heavy ion-irradiated zeolites and ceramics.

\section{Experimental}

The samples were prepared in Zagreb, PALS measurements were performed in Budapest and Zagreb, the swift ion irradiations were done in Dubna. Gel samples (type III) were obtained by mixing the silicate and aluminate components at room temperature (RT). This gel was hermetically closed and heat treated at $373 \mathrm{~K}$ for $240 \mathrm{~min}$, yielding in the sodium form of zeolite A (or LTA). The preparation of the samples and the exchange of $\mathrm{Na}^{+}$with $\mathrm{NH}_{4}^{+}, \mathrm{Li}^{+}, \mathrm{K}^{+}, \mathrm{Cs}^{+}$, $\mathrm{Rb}^{+}$, and $\mathrm{Cu}^{+}$is described in Refs. [5-8]. The zeolite powders were pressed at $7.540 \mathrm{MPa}$ into tablets. Recrystallization of zeolite samples to ceramics was performed by high-temperature baking out at the exothermic peak temperatures, determined by differential scanning calorimetry (DSC). The ceramics samples were irradiated (up to a penetration depth of $c a$. $20 \mu \mathrm{m}$ ) with Bi ions at $670 \mathrm{MeV}$ energy with $4 \times 10^{12} \mathrm{ion} / \mathrm{cm}^{2}$ fluence. After irradiation, long enough waiting times were observed to allow for the decay of short-lived radioactivity of the irradiated samples. The samples were prepared sandwiching the ${ }^{22} \mathrm{Na}$ source $(0.5-2.0 \mathrm{MBq}$ packed mid thin $\mathrm{Ti}$ or $\mathrm{Al}$ foils) between two tablets, wrapped in Al-foil. LT measurements were performed in vacuum at RT, and also after heat treatment in vacuum at $533 \mathrm{~K}$ and $593 \mathrm{~K}$ to ensure degassing of water. The fast-fast coincidence ORTEC LT spectrometer (featuring XP 2020 URQ photomultipliers equipped with $1^{\prime \prime} \times 1^{\prime \prime} \mathrm{NE} 111$ and $\mathrm{BaF}_{2}$ scintillators, respectively) assured efficient recording of $3 \gamma$-events [9] with ca. 260 ps FWHM resolution for ${ }^{60}$ Co. In those cases, where no long-lived lifetime components were observed, the LT spectra were collected with lower detection efficiency but better time resolution ( $210 \mathrm{ps}$ FWHM for ${ }^{60} \mathrm{Co}$ ). For samples with long lifetime components a time range of $1 \mu \mathrm{s}$, for the "short lifetime" cases $100 \mathrm{~ns}$ or $50 \mathrm{~ns}$ ranges were selected. Integral counts of $3 \times 10^{6}-1 \times 10^{7}$ were collected. The LT spectra were recorded in a Microfast $16 \mathrm{k}$ PC MCA and were analyzed with the LT (v. 9) program [10].

\section{Results and discussion}

It was found that a satisfactory LT fit for zeolite precursor gels requires in most cases four lifetime components, for $\tau_{1}$ (combining $p$-Ps and $\mathrm{e}^{+}$annihilations) typically $0.2-0.5 \mathrm{~ns}$, for $\tau_{2}$ (denoting $o$-Ps trapped in microvoids) $c a .0 .9-1.5 \mathrm{~ns}$, for 
$\tau_{3}$ (resulting from $o$-Ps decaying in internal channels of the zeolites) approximately 5-10 ns and for $\tau_{4}$ (probably originating from $o$-Ps decaying in the intergrain space) up to 40-90 ns. The latter components have relatively high intensities (4-5\%) in gel samples (Table). The different alkali ions have different size, which probably cannot modify much the long lifetime components due to geometrical effects but may influence the $o$-Ps interactions through the modified electron structure.

TABLE

Lifetime results for gel, irradiated (irr.) and reference recrystallized zeolite samples. Lifetimes $\tau_{i}$ are given in [ns], intensities $I_{i}$ in [\%]. The relative errors are less than $5 \%$.

\begin{tabular}{|c|c|c|c|c|c|c|c|c|}
\hline Sample & $\tau_{1}$ & $\tau_{2}$ & $\tau_{3}$ & $\tau_{4}$ & $I_{1}$ & $I_{2}$ & $I_{3}$ & $I_{4}$ \\
\hline $\mathrm{Na}$ III gel & 0.24 & 0.63 & 3.76 & 91.1 & 38.5 & 46.6 & 7.6 & 7.3 \\
\hline $\begin{array}{l}\text { Na A (1173 K) } \\
\text { (low-carnegieite) }\end{array}$ & 0.181 & 0.453 & 1.55 & 9.86 & 57.3 & 38.8 & 3.24 & 0.69 \\
\hline $\mathrm{Na} A$ irr. & 0.183 & 0.401 & 0.846 & - & 28.7 & 60.4 & 10.9 & - \\
\hline Cs III gel & 0.32 & 1.02 & 5.47 & 44.6 & 75.7 & 17.8 & 2.5 & 4.0 \\
\hline $\begin{array}{l}\text { Cs A }(1330 \mathrm{~K}) \\
\text { (pollucite) }\end{array}$ & 0.188 & 0.464 & 1.32 & 11.7 & 41.7 & 44.5 & 12.9 & 0.88 \\
\hline $\begin{array}{l}\mathrm{Cu} \mathrm{A}(1366 \mathrm{~K}) \\
\left(\mathrm{CuAl}_{2} \mathrm{O}_{4}+\text { cristobalite }\right)\end{array}$ & 0.203 & 0.388 & 1.41 & - & 61.9 & 37.8 & 0.27 & - \\
\hline $\mathrm{Cu} \mathrm{A}$ irr. & 0.171 & 0.339 & 0.99 & - & 56.3 & 43.2 & 0.52 & - \\
\hline K III gel & 0.33 & 1.01 & 6.47 & 74.7 & 74.2 & 21.9 & 1.6 & 2.2 \\
\hline $\begin{array}{l}\text { K A }(1237 \mathrm{~K}) \\
\text { (kalsilite+kaliophilite) }\end{array}$ & 0.158 & 0.372 & 1.02 & 3.8 & 27.1 & 52.6 & 19 & 1.26 \\
\hline K A irr. & 0.184 & 0.392 & 0.988 & - & 36.2 & 45 & 18.8 & - \\
\hline Li III gel & 0.3 & 0.88 & 5.21 & 70 & 67.2 & 27.7 & 2.1 & 2.9 \\
\hline $\begin{array}{l}\text { Li A (1095 K) } \\
\text { (amorphous) }\end{array}$ & 0.192 & 0.465 & 1.11 & 9.4 & 37.1 & 48.3 & 13.8 & 0.87 \\
\hline Li A irr. & 0.195 & 0.426 & 0.921 & - & 26.6 & 52.5 & 20.9 & - \\
\hline $\mathrm{NH}_{4}$ III gel & 0.28 & 0.72 & 2.72 & 36.5 & 62.6 & 27.8 & 5.5 & 4.1 \\
\hline $\begin{array}{l}\mathrm{NH}_{4} \mathrm{~A}(1273 \mathrm{~K}) \\
\left(\mathrm{SiO}_{2}+\text { mullite }\right)\end{array}$ & 0.216 & 0.512 & 1.33 & 13.7 & 44.9 & 41.2 & 13.2 & 0.73 \\
\hline $\mathrm{NH}_{4} \mathrm{~A}$ irr. & 0.244 & 0.504 & 1.11 & - & 43.9 & 40 & 16.1 & - \\
\hline Rb III gel & 0.29 & 0.83 & 3.39 & 39.7 & 70.6 & 21.5 & 3.7 & 4.3 \\
\hline $\begin{array}{l}\mathrm{Rb} A(1328 \mathrm{~K}) \\
\left(\mathrm{RbAlSiO}_{4}\right)\end{array}$ & 0.215 & 0.536 & 1.36 & 14.5 & 48.2 & 41.6 & 9.42 & 0.76 \\
\hline Rb A irr. & 0.197 & 0.427 & 1.03 & - & 38.4 & 45.4 & 16.2 & - \\
\hline
\end{tabular}


For high temperature heat treated zeolite samples the porous structure recrystallized to a compact one, reflected in a reduction of the long components as shown in Table, also listing the heat treatment temperatures and the resulting structures.

In the case of dense solids swift heavy ion irradiation can induce longer lifetime components due to the free volume generated by the ion tracks. However, the lifetimes became shorter after irradiation than they were before for the samples in Table, the longest components practically disappeared (Fig. 1). The LT

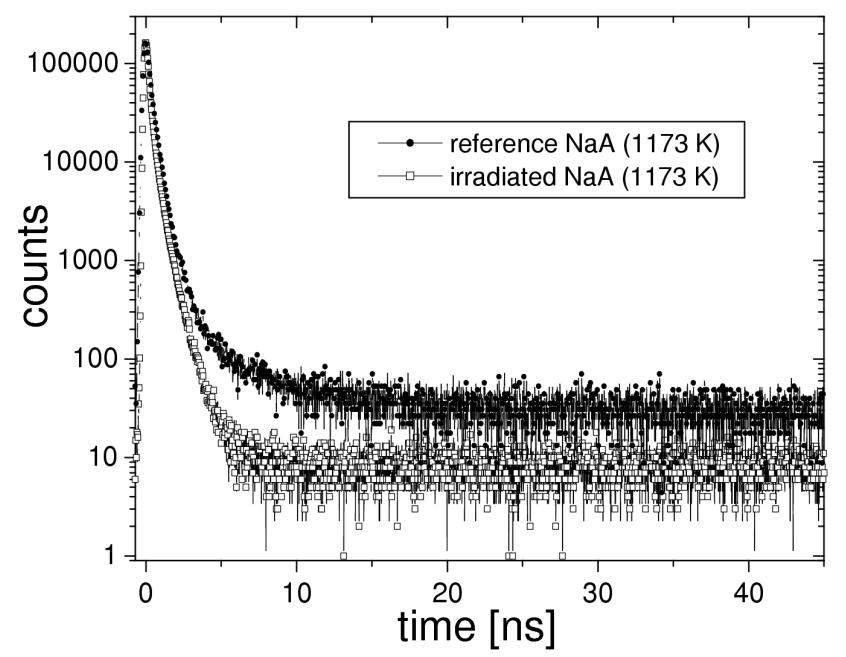

Fig. 1. LT spectra of the reference (un-irradiated) and irradiated sodium A-type zeolite (recrystallized at $1173 \mathrm{~K}$ ). The samples were heat treated in vacuum at $533 \mathrm{~K}$.

measurements were repeated after vacuum heat treatment at higher temperatures (593 K instead of $533 \mathrm{~K}$ ). The results did not change substantially, in accordance with earlier results published for similar samples [11]. The thickness of the samples is $3 \mathrm{~mm}$, larger than the primarily ion-irradiated and destroyed region, positrons from the ${ }^{22} \mathrm{Na}$ penetrate deeper into the samples than the Bi ions. The other, non-irradiated side of the samples was also measured and no significant differences were found. X-ray diffraction (XRD) spectra showed that after irradiation the $\mathrm{X}$-ray peaks were only slightly shifted as compared to the non-irradiated samples, revealing the presence of stress but also that the crystal structure survived the irradiation, i.e., the disappearance of the long lifetime components cannot result from structural changes. A similar lifetime shortening in alumina powders due to irradiation was reported in [12] and it was ascribed to quenching of surface-bound $o$-Ps by irradiation-created interstitial atoms migrating to the surface. Similar effects were interpreted as a consequence of reaction with paramagnetic centers on the surfaces in $\mathrm{SiO}_{2}$ [13] and in fine oxide grains [14]. Our samples are rich in internal grain surfaces and they contain elements ( $\mathrm{Al}, \mathrm{Si}, \mathrm{O})$ suitable for these 
effects. The long-lived $o$-Ps can take part in spin-conversion processes also with unpaired electrons [15-17]. In our case, the F-centers or dangling bonds of $\mathrm{Si}$ created by the secondary $\gamma$ and X-ray radiation can behave as unpaired electrons. The "equality" of LT spectra recorded from the face and the back side of the samples might be explained recapitulating that the swift heavy ion irradiation has activated the sample and during the decay of the short-lived radioactive isotopes their radiation may fully penetrate the sample volume creating a homogeneous distribution of the agents referred to above.

\section{Conclusions}

PALS is a sensitive method for free-volume investigation but in irradiated samples special care is needed. The long-lived $o$-Ps can take part in various conversion interactions facilitated by different irradiation-induced defects and also by the presence of internal grain surfaces probably enriched in the radiation-induced Ps-quenching agents. These effects result in short lifetimes, and can obscure the free volume sensitivity of PALS. Although the LTA structure itself ensures the trapping sites accommodating long-lived $o$-Ps states due to the interactions of $o$-Ps with the agents set free by the swift heavy ion irradiation, those trapping sites become hidden. However, the significant reduction of the long lifetime components may give a possibility to monitor the radiation damage with PALS.

The results presented here on ceramics and irradiated ceramics represent only a part of the systematic studies still in progress.

\section{Acknowledgments}

Partial supports within the frames of Hungarian-Portuguese (P-23/03 and P-23/05) and Hungarian-Croatian (HR-1/2004) bilateral research agreements are gratefully acknowledged. The Hungarian Academy of Sciences-Dubna JINR research agreement supported the sample irradiations in Dubna. Contributions through research grants of OTKA (T 029215, T 030327, T 032029, T 032249, $\mathrm{T}$ 046238, K 68414) and in Croatia by the Ministry of Science, Education and Sports, contract Nos. 0119259, A679078 and 0098060 were essential. Discussions with Prof. G. Duplâtre, Dr. L. Varga, assistance in sample preparation by Dr. B. Molnár and Ms. Cs. Bogdány are thankfully acknowledged.

\section{References}

[1] S.J. Tao, J. Chem. Phys. 56, 5499 (1972).

[2] M. Eldrup, D. Lightbody, J.N. Sherwood, Chem. Phys. 63, 51 (1981).

[3] D.W. Gidley, W.E. Frieze, A.F. Yee, E.T. Ryan, H.M. Ho, Phys. Rev. B 60, R5157 (1999).

[4] T. Goworek, K. Ciesielski, B. Jasińska, J. Wawryszczuk, Radiat. Phys. Chem. 58, 719 (2000). 
[5] C. Kosanović, A. Čižmek, B. Subotić, I. Šmit, M. Stubičar, A. Tonejc, Zeolites 15, 632 (1995).

[6] C. Kosanović, A. Čižmek, B. Subotič, I. Šmit, Thermochim. Acta 317, 25 (1998).

[7] P.S. Singh, T.L. Dowling, J.N. Watson, J.W. White, Phys. Chem. Chem. Phys. 1, 4125 (1999).

[8] C.S. Cundy, Stud. Surf. Sci. Catal. 157, 65 (2005).

[9] L. Liszkay, Zs. Kajcsos, G. Duplâtre, K. Lázár, G. Pál-Borbély, H.K. Beyer, Mater. Sci. Forum 363-365, 377 (2001).

[10] J. Kansy, Nucl. Instrum. Methods Phys. Res. A 374, 235 (1996).

[11] Zs. Kajcsos, C. Kosanović, L. Liszkay, P. Major, L. Lohonyai, P. Zalán, K. Lázár, S. Bosnar, B. Subotić, D. Bosnar, K. Havancsák, P.M. Gordo, T. Tomašić, Phys. Status Solidi C 4, 3810 (2007).

[12] C. Dauwe, Mbungu-Tsumbu, Phys. Rev. B 45, 45 (1992).

[13] H. Saito, Y. Nagashima, T. Hyodo, T. Chang, Phys. Rev. B 52, R689 (1995).

[14] H. Saito, T. Hyodo, Phys. Rev. B 60, 11070 (1999).

[15] P.R. Wallace, Solid State Phys. 10, 1 (1960).

[16] M. Katimoto, T. Hyodo, T. Chiba, T. Akahane, T.B. Chang, J. Phys. B 20, L107 (1987).

[17] M. Katimoto, T. Hyodo, T.B. Chang, J. Phys. B 23, 589 (1990). 